\title{
Idiopathic Intracranial Hypertension in Asians: A New Perspective and the Need for Scrutiny
}

\author{
Ki Baek Lee, $\mathrm{PhD}^{1}$, Soo Jeong, $\mathrm{MD}^{2}$, Deok Hee Lee, $\mathrm{MD}, \mathrm{PhD}^{2}$ \\ ${ }^{1}$ Biomedical Engineering Research Center, Asan Institute for Life Sciences, Asan Medical Center, Seoul, Korea \\ ${ }^{2}$ Department of Radiology, Research Institute of Radiology, Asan Medical Center, University of Ulsan College of Medicine, Seoul, Korea
}

While reviewing the clinical settings of typical idiopathic intracranial hypertension $(\mathrm{IH})$, we found that there was a gap between the reports from Western countries and our domestic clinical experience. 'The typical description of $\mathrm{IH}$ is as follows: a rare condition of unknown cause, which causes increased intracranial pressure (ICP), and is characterized by symptoms related to increased ICP, especially in young obese females aged 25-45 years., ${ }^{2,3}$ Furthermore, they suggested that a reason for the recent increase in disease incidence in Western society was probably due to the rapid increase in the obese population. ${ }^{4}$ In our clinical experience, however, we seldom experience morbid obesity in $\mathrm{IH}$ patients, the trend of which seems a little different from typical reports so far. Although we read a case report published in 2018 by Miyachi et al. ${ }^{5}$ with interest several years ago, we failed at the time to pay attention to the body habitus of 2 young Japanese female patients described in the report. One patient was a 27-year-old female $165 \mathrm{~cm}$, $48 \mathrm{~kg}$ ), and the other was a 17-yearold young female $(163 \mathrm{~cm}, 54 \mathrm{~kg})$. Their body-mass indices were $17.6 \mathrm{~kg} / \mathrm{m}^{2}$ and $20.3 \mathrm{~kg} / \mathrm{m}^{2}$, respectively. The authors had already mentioned in the report that some other etiology of $\mathrm{IH}$ apart from obesity must be present. This observation suggests the need for having an Asian perspective in the management of medically refractory $\mathrm{IH}$ patients. Since the control of other risk factors of increased ICP is a prerequisite for the long-term durability of a stenting procedure, they emphasized the importance of persistent weight control and management of other risk factors, including obstructive sleep apnea. In reports from Western countries, the importance of weight control has been emphasized for the long-term durability of initially responsive dural sinus stenting. ${ }^{6}$ Even bariatric surgery is considered in a refractory situation. However, measures to be taken for Asian patients, who are not overweight or may essentially be underweight, are unclear. Although Miyachi et al. ${ }^{5}$ reported a good initial clinical response in both Asian patients, we believe they should follow up these 2 patients in the long term since dural sinus stenting is not a curative treatment for $\| \mathrm{H}$. Since stenting of a collapsed sinus lumen only helps cut the vicious cycle of increased ICP, which is aggravated by secondary venous hypertension caused by extrinsic compression of the sinus, the risk of consecutive sinus lumen col-

\section{Correspondence to: Deok Hee Lee, MD, PhD Department of Radiology, Research Institute of Radiology, Asan Medical Center, University of Ulsan College of Medicine, 88 Olympic-ro 43-gil, Songpa-gu, Seoul 05505, Korea Tel: +82-2-3010-5944 \\ Fax: +82-2-476-0090 \\ E-mail:dhlee@amc.seoul.kr}

Received: December 18, 2021

Revised: January 25, 2022

Accepted: January 26, 2022

\begin{abstract}
Copyright @ 2022 Korean Society of Interventional Neuroradiology

This is an Open Access article distributed under the terms of the Creative Commons Attribution Non-Commercial License (http://creativecommons.org/licenses/by-nc/4.0) which permits unrestricted non-commercial use, distribution, and reproduction in any medium, provided the original work is properly cited.
\end{abstract}

pISSN 2093-9043 eISSN 2233-6273 
lapse at a non-stent segment of the sinuses remains. ${ }^{7}$ Therefore, it is important to control the ICP stably after successful sinus stenting. ${ }^{8}$ In this regard, identifying risk factors other than obesity in Asian patients is important. Possible risk factors, such as drug-related $\mathrm{IH}$, have already been listed. ${ }^{9}$ Our role should be extended to the scrutinization of defining the exact cause. Furthermore, the role should also be extended in solving the enigmatic pathomechanism of this disease. We believe understanding the recently proposed concept of the glymphatic system could be undertaken as a priority for now. ${ }^{10}$

\section{Fund}

None.

\section{Ethics Statement}

This study waived approval from the institutional review board. Informed consent for publication is not required.

\section{Conflicts of Interest}

The authors have no conflicts to disclose.

\section{Author Contributions}

Concept and design: KBL and DHL. Data collection: SJ. Writing the article: KBL and DHL. Critical revision of the article: SJ and DHL. Final approval of the article: DHL. Overall responsibility: DHL.

\section{ORCID}

Ki Baek Lee: https://orcid.org/0000-0002-6953-0582

Soo Jeong: https://orcid.org/0000-0003-2050-5156

Deok Hee Lee: https://orcid.org/0000-0003-0355-0449

\section{REFERENCES}

1. Kim TW, Choung HK, Khwarg SI, Hwang JM, Yang HJ. Obesity may not be a risk factor for idiopathic intracranial hypertension in Asians. Eur J Neurol 2008;15:876-879

2. Wakerley BR, Mollan SP, Sinclair AJ. Idiopathic intracranial hypertension: update on diagnosis and management. Clin Med (Lond) 2020;20:384-388

3. Markey KA, Mollan SP, Jensen RH, Sinclair AJ. Understanding idiopathic intracranial hypertension: mechanisms, management, and future directions. Lancet Neurol 2016;15:78-91

4. Miah L, Strafford H, Fonferko-Shadrach B, Hollinghurst J, Sawhney IM, Hadjikoutis S, et al. Incidence, prevalence and healthcare outcomes in idiopathic intracranial hypertension: a population study. Neurology 2021;96:e1251-e1261

5. Miyachi S, Hiramatsu R, Ohnishi H, Takahashi K, Kuroiwa T. Endovascular treatment of idiopathic intracranial hypertension with stenting of the transverse sinus stenosis. Neurointervention 2018;13:138-143

6. Hoffmann J, Mollan SP, Paemeleire K, Lampl C, Jensen RH, Sinclair AJ. European headache federation guideline on idiopathic intracranial hypertension. J Headache Pain 2018;19:93

7. Fargen KM. Idiopathic intracranial hypertension is not idiopathic: proposal for a new nomenclature and patient classification. $J$ Neurointerv Surg 2020;12:110-114

8. Kahan J, Sundararajan S, Brown K, Dinkin M, Oliveira C, Patsalides $A$. Predicting the need for retreatment in venous sinus stenting for idiopathic intracranial hypertension. J Neurointerv Surg 2021;13:574-579

9. Tan MG, Worley B, Kim WB, Ten Hove M, Beecker J. Drug-induced intracranial hypertension: a systematic review and critical assessment of drug-induced causes. Am J Clin Dermatol 2020;21:163-172

10. Taoka T, Naganawa S. Neurofluid dynamics and the glymphatic system: a neuroimaging perspective. Korean J Radiol 2020;21:1199-1209 